\title{
Analysis of heat exchanger in an air handling unit - A case study
}

\author{
Marek Borowski ${ }^{1}$, Klaudia Zwolińska ${ }^{1 *}$, and Marcin Czerwiński $^{2}$ \\ ${ }^{1}$ Faculty of Civil Engineering and Resource Management, AGH University of Science and Technology, \\ 30-059 Kraków, Poland \\ ${ }^{2}$ Frapol Sp. z o.o., 30-832 Kraków, Poland
}

\begin{abstract}
Ventilation plays an important role in providing comfortable conditions for users and is also one of the most energy-consuming systems in the building. Due to successive regulations aimed at reducing the energy load of buildings towards zero-energy buildings, energy recovery systems in air handling units have become an indispensable element. The high effectiveness of the entire system guarantees a reduction in energy demand. At very low or very high external temperatures, appropriate comfort conditions are provided by additional heaters or coolers. The subject of the paper is a ventilation system in a hotel located in southern Poland. The building is a faithful reconstruction of the historical saltworks adapted for the needs of the hotel. The air handling unit equipped with a rotary exchanger supplies air to hotel rooms located on two floors. The analysis includes the effectiveness of the air-handling unit operation under various external conditions, as well as the temperature changes during heat exchange. The results show the actual operation of the airhandling unit, which is particularly important in terms of reducing the energy consumption of the hotel.
\end{abstract}

\section{Introduction}

Reducing the energy consumption of buildings is an issue that has become increasingly important in recent years. Building construction and operations accounted for the largest share of both global final energy use $(36 \%)$ in 2018. Consequently, it is also responsible for significant emissions of pollutants into the atmosphere [1]. To improve the energy performance of buildings, a comprehensive legislative framework in this field has been established. The Energy Performance of Buildings Directive 2010/31/EU [2] and the Energy Effectiveness Directive 2012/27/EU [3] include the essential regulation in this area. The main aim of the documents is to reduce building energy consumption, achieve high energy effectiveness in this sector, and increase the popularity of renewable energy sources. All this is expected to increase the use of the so-called clean energy generation technologies, and to reduce greenhouse gas emissions into the atmosphere. Buildings must meet energy performance requirements set out in established documents. It has a direct impact on the building structures as well as the effectiveness of the applied devices. According to the Directive, applicable in all Member States, after 2021 all new buildings should be nearly zero-energy buildings. In the case of new buildings occupied and owned by public authorities, this requirement came into force as early as 2019. The same document defines nZEB as a building with very high energy performance, where energy demand to a large extent is covered by energy from renewable sources.

The main purpose of ventilation in a building is to provide comfortable conditions for users by supplying fresh air and extracting exhaust air. Unfortunately, around $30 \%$ of a building's energy is lost in ventilation and exfiltration [4]. Therefore, the ventilation system design process includes not only the selection of an optimal solution to provide appropriate air parameters but also takes into consideration environmental and economic aspects.

The most common solution to limit ventilation-related energy consumption is using heat recovery devices, therefore, there are many studies about this topic. Depending on the applied design solutions and materials, the heat exchangers can vary in effectiveness coefficients. Hence new solutions appear on the market to increase savings [5]. The research of Hunt et al. [6] presents the thermal performance characterization of a reverse-flow energy recovery ventilator for residential buildings in cold climates. For this solution, the enthalpy ratio varied from $72.8 \%$ to $88.6 \%$. The temperature and humidity ratio ranged from $86.0 \%$ to $92.9 \%$ and from $9.8 \%$ to $77.1 \%$, respectively. The highest recorded results during the measurements were $88.6 \%$ for temperature ratio, $92.9 \%$ for humidity ratio, and $77.1 \%$ for total recovery ratio. An analysis of a heat exchanger efficiency in laboratory conditions was also the subject of research in the work of Borowski et al. [7]. Measurements of temperature, humidity, and air volume flow rates were carried out. Based on the experimental data, the sensible and latent heat recovery ratios at the cold environment amounted to $96.3 \%$ and $79.8 \%$, respectively. The authors underlined that the proposed heat exchanger is the solution that helps to meet nearly zero energy buildings requirements for new buildings. The efficiency of the ventilation system was also analysed in the research of Michalask and

\footnotetext{
* Corresponding author: kzwolinska@agh.edu.pl
} 
Grygierczyk [8]. The authors presented the thermal performance of the two air-handling units in the passive building. The average annual temperature effectiveness of heat recovery for the unit equipped with a rotary exchanger was $47.2 \%$ and for the cross-flow exchanger, it was $80.1 \%$. A similar comparison was presented in the paper by Zemitis and Borodinecs [9]. The authors compared two types of heat exchangers supplied by different manufacturers: rotary and counter-flow. The data used in this study is heat recovery temperature effectiveness at various air flow volumes declared by the producers for the cold region. This paper showed that the average heat recovery effectiveness of modern, commonly used rotary heat exchangers is around $83 \%$, while for counter-flow exchangers around $86 \%$.

In addition to the efficiency analysis, the research for cross-flow exchangers includes often tests of the antiicing system. The anti-icing system is the subject of the work of Jaszczur et al. [10]. The authors analysed the temperature and humidity distribution during the operation of the anti-icing system of the air handling unit equipped with a counter-flow heat exchanger.

The main aim of the study is to analyse the operation condition of the air handling unit in a hotel building located in southern Poland. Based on the measurements, the heat exchanger effectiveness was evaluated. In the paper, the sensible, latent, and total heat transfer effectiveness of air handling units equipped with reverse regenerative heat exchangers were presented.

\section{Methodology}

The subject of the research is the ventilation system in a hotel located in southern Poland. Due to the size and purpose of the building, ventilation is provided by several air handling units. The work takes into account the operating parameters of the air handling unit supplying air to hotel rooms. The proposed air handling unit is equipped with a regenerative counterflow exchanger with controlled humidity recovery. Experimental measurements of the system were carried out to determine the temperature, humidity, and total effectiveness of the ventilation unit with heat recovery. The tests were carried out under real conditions during the normal operation of the hotel and continuously with a reading period of 1 minute. Figure 1 shows a simplified diagram and marking of the tested parameters.

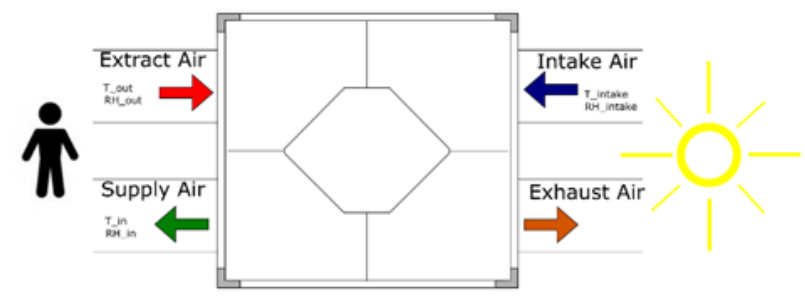

Fig. 1. Schematic diagram of the data collection and nomenclature

In the cold season, the operation of the ventilation system is related to the highest losses of thermal energy. Hence, the periods with average daily temperatures below
$5{ }^{\circ} \mathrm{C}$ were selected for further analysis. For this purpose, the so-called typical meteorological year for the closest meteorological station was used. These data were prepared on the basis of the EN ISO 15927: 4 [11] standard and made public by the Ministry of Investment and Development. A typical meteorological year for the nearest station is shown in Figure 2.

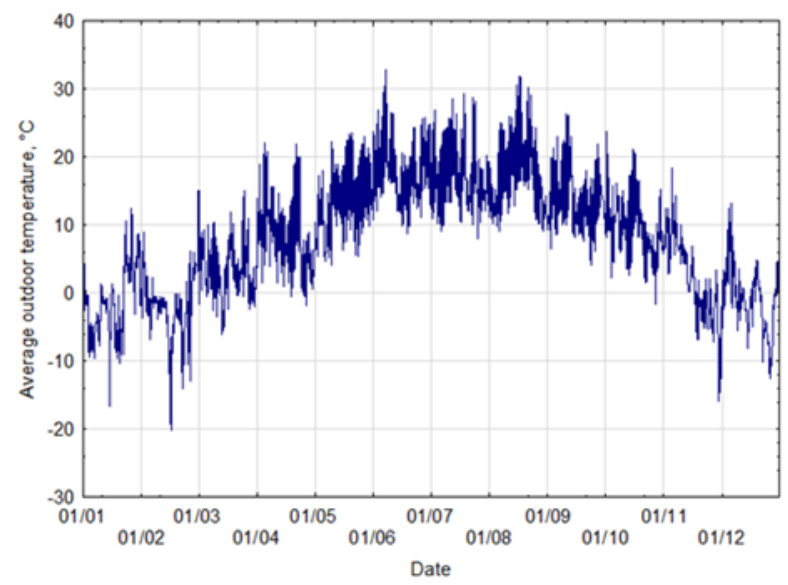

Fig. 2. A typical meteorological year for the weather station Kraków Balice

Based on the above considerations, the periods from January to March and from November to December were adopted for further calculation. In these months, the lowest temperatures were observed. From each of the analysed months, three days were selected. Based on the temperatures and humidity recording data, the system effectiveness was determined. Table 1 presents the basic information of the analysed system and the study period. The ventilation system works in a balanced mode. Therefore, the intake and outtake airflows are equals. The air stream volumes were monitored on an ongoing basis during the operation of the air handling unit. The average volumetric flow recorded during the measurements was $2500 \mathrm{~m}^{3} / \mathrm{h}+/-5 \%$.

Table 1. Condition during the measurements

\begin{tabular}{|c|c|c|c|c|}
\hline \multirow{2}{*}{$V_{-I n t a k e}\left(\mathrm{~m}^{3} / \mathrm{h}\right)$} & \multicolumn{2}{|c|}{$\mathrm{T} \_$Intake $\left({ }^{\circ} \mathrm{C}\right)$} & \multicolumn{2}{c|}{ RH_Intake $\left({ }^{\circ} \mathrm{C}\right)$} \\
\cline { 2 - 5 } & Min & Max & Min & Max \\
\hline $\begin{array}{c}2500 \\
+/-5 \%\end{array}$ & -2.77 & 22.40 & 28.90 & 97.00 \\
\hline
\end{tabular}

The air temperature and relative humidity measurements were performed by using CR-22 transducers. The temperature of the air was measured by using NTC10k sensors. The control of the volume stream of ventilation streams was possible thanks to the DPT2500-R8 differential pressure transducer.

In the next stage, commonly known equations were used to estimate the effectiveness of heat recovery. To determine the heat and mass transfer in the air handling unit, the moisture content and enthalpy of each air stream were calculated according to the description below.

Moisture content in the air, i.e., mass of the moisture in the air to the dry air mass, was determined using Dalton's law and the gas equation of state. This parameter can be expressed in terms of total pressure and ambient 
water vapor pressure [12]. The values were calculated based on temperature and relative humidity, as shown below:

$$
x=0.622 \cdot \frac{R H \cdot p_{w s}}{p-R H \cdot p_{w s}}
$$

The enthalpy of humid air with the moisture content $x$ can be defined as the sum of the components: water vapor and dry air. The moist air specific enthalpy can be calculated with the below equation [12]:

$$
h=1.006 \cdot T+x(2501+1.86 T), k J / k g
$$

Generally, effectiveness can be defined as [13]:

$$
\eta=\frac{\text { actual transfer of energy or moisture }}{\text { maximum possible transfer }}
$$

According to the above equation, three indicators characterizing the energy transfer were used: sensible effectiveness, latent effectiveness, and total transfer effectiveness. Below these ratios are detailed described [13].

Sensible effectiveness is the ratio of the heat transferred between two airstreams to the maximum possible amount of heat that could be hypothetically recovered. In this way, only the transfer of sensible heat energy related to the temperature difference between the airstreams is included. This factor can be calculated as:

$$
\eta_{T}=\frac{\dot{M}_{\text {in }} c_{p, \text { in }}\left(T_{\text {in }}-T_{\text {intake }}\right)}{\dot{M}_{\min } c_{p, \min }\left(T_{\text {out }}-T_{\text {intake }}\right)}
$$

Latent effectiveness is used to evaluate the moisture transferred in the heat exchanger and can be calculated analogously to sensible effectiveness according to the following formula:

$$
\eta_{H}=\frac{\dot{M}_{\text {in }}\left(x_{\text {in }}-x_{\text {intake }}\right)}{\dot{M}_{\min }\left(x_{\text {out }}-x_{\text {intake }}\right)}
$$

Enthalpy transfer effectiveness is a total energy transfer effectiveness that expresses the heat and mass transfer. It is given by the formula:

$$
\eta_{T O T}=\frac{\dot{M}_{\text {in }}\left(h_{\text {in }}-h_{\text {intake }}\right)}{\dot{M}_{\min }\left(h_{\text {out }}-h_{\text {intake }}\right)}
$$

According to the assumptions of a balanced flow, the supply and exhaust airflows are equal. In further calculation, the ratio of the mass flows in the above formulas is equal to 1 .

\section{Results and discussion}

The performance analysis of air handling units in real conditions is a very difficult task due to many factors that change independently and in a very dynamic way. Based on the collected data and the selection of the most representative samples during the year, the effectiveness of the applied heat recovery system was determined. In the first stage of the paper, the recorded temperature and humidity measurements of three airstreams: intake, supply, and exhaust air, were analysed. Due to the difficulties in comparing the relative humidity of the air, all values were calculated to moisture content expressed in $\mathrm{kg} / \mathrm{kg}$ of dry air.

Figure 3 shows the daily temperature distribution, based on the example of January 18, 2020. Both the supply and exhaust air temperatures are relatively constant values, which is required to ensure comfort conditions for users. The supply air temperature varies within a narrow range from 19 to $21.5^{\circ} \mathrm{C}$. Much greater changes are noticeable in the intake air, as it changes from -1.5 to $3.9^{\circ} \mathrm{C}$. Despite the fluctuations, it does not have a significant effect on the supplied air temperature values.

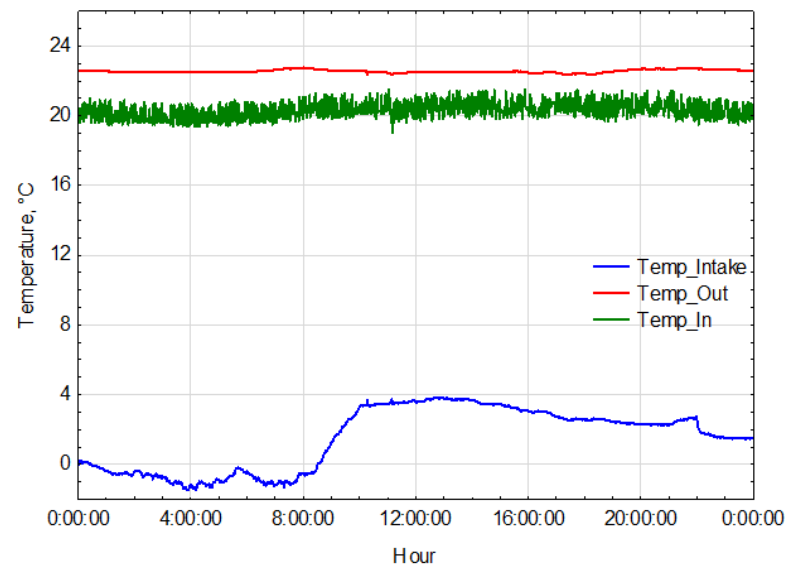

Fig. 3. Daily temperature variability of intake, extract, and supply air - an example of a diagram (18 January 2020)

Likewise, Figure 4 shows how the moisture content in the air changes. In this case, there is a clear relationship between the moisture content of the streams, and the course of the daily cycle is apparently similar. Any increase in humidity of the intake airstream or exhaust airstream directly affects the humidity of the air supplied to the room.

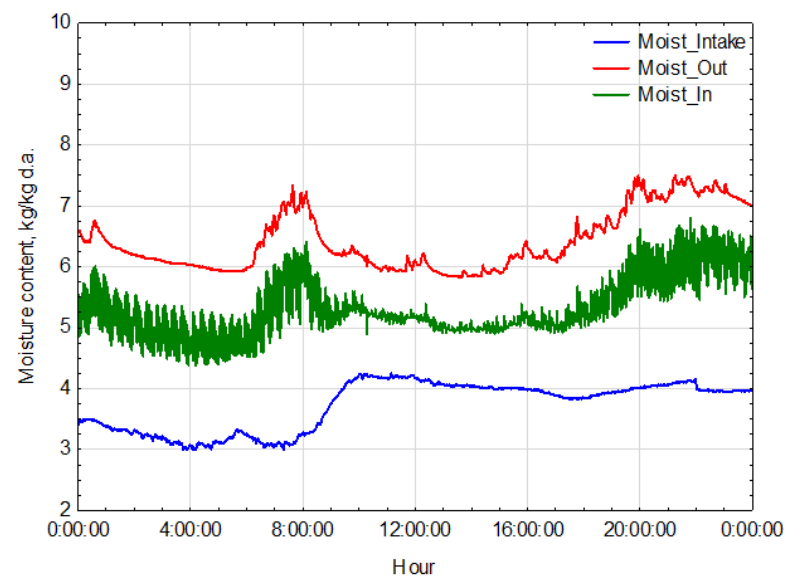

Fig. 4. Daily moisture content variability of intake, extract, and supply air - an example of a diagram (18 January 2020)

Similarly for the above case, Figures 5 and 6 show the results for the period of November 18-19, 2020. In this period, the large variability of air temperature is visible because it is a transitional period in the polish climate. The 
temperature during this time varies from $2.6{ }^{\circ} \mathrm{C}$ to $16.1^{\circ} \mathrm{C}$. On the example of this measurement period, the influence of the intake air temperature on the temperature of the supply air is significantly visible. The distribution of the moisture content, analogically to the previous diagrams, shows a significant dependence between the moisture content in each of the airstreams.

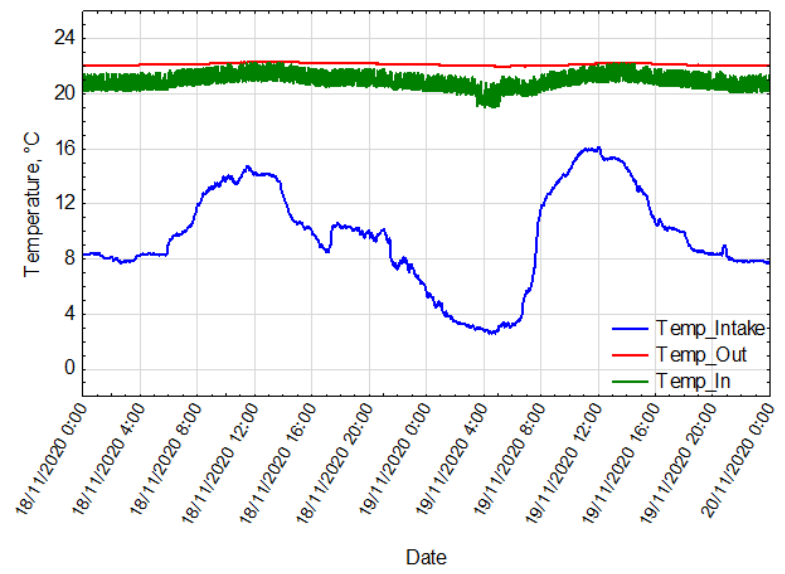

Fig. 5. Temperature variability of intake, extract and supply air between 18 and 19 November

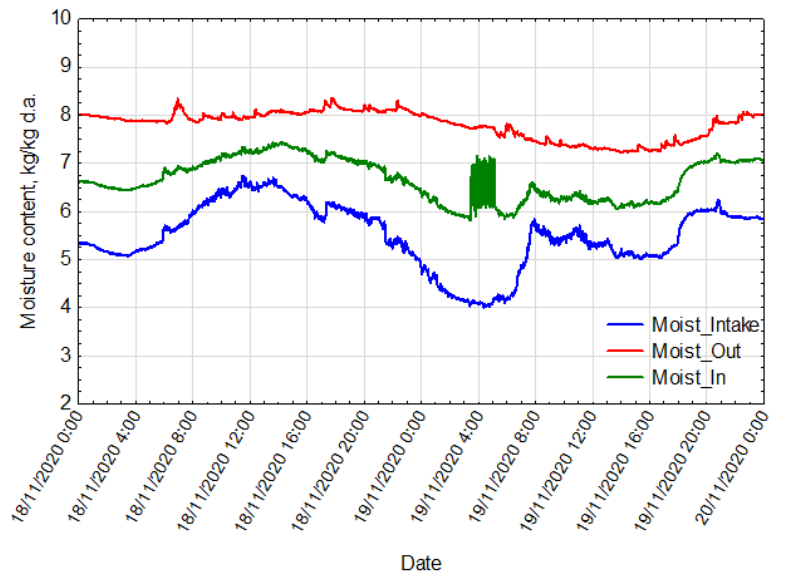

Fig. 6. Moisture content variability of intake, extract and supply air between 18 and 19 November

Table 2 shows the minimum and maximum temperature and humidity values for each of the three streams. As can be seen from the table, even though the winter and transitional seasons were only included in the analysis, the recorded temperatures during the day could even exceed $20^{\circ} \mathrm{C}$.

Table 2. Maximum and Minimum Temperature and Humidity Values for each Airstream

\begin{tabular}{|c|c|c|c|c|}
\hline \multirow{2}{*}{ Airstream } & \multicolumn{2}{|c|}{$\mathrm{T}\left({ }^{\circ} \mathrm{C}\right)$} & \multicolumn{2}{c|}{$\mathrm{x}(\mathrm{kg} / \mathrm{kg}$ d.a. $)$} \\
\cline { 2 - 5 } & $\mathrm{Min}$ & $\mathrm{Max}$ & $\mathrm{Min}$ & $\mathrm{Max}$ \\
\hline Intake air,_Intake & -2.8 & 22.4 & 2.9 & 6.9 \\
\hline Supply air,_In & 12.1 & 23.9 & 4.1 & 9.1 \\
\hline Extract air,_Out & 19.5 & 24.0 & 5.0 & 10.1 \\
\hline
\end{tabular}

Based on the above-mentioned formulas and collected data, the effectiveness of the device was calculated. Table 3 presents a summary of the average effectiveness for the studied period. The average value of the total effectiveness in real conditions is $80 \%$, which is a very good result compared to other heat exchangers.

Table 3. Average effectiveness of the heat exchange

\begin{tabular}{|c|c|}
\hline Effectiveness & Average \\
\hline Temperature $\eta_{\mathrm{T}}$ & 0.8814 \\
\hline Humidity $\eta_{\text {H }}$ & 0.5511 \\
\hline Total $\eta_{\text {Tот }}$ & 0.8002 \\
\hline
\end{tabular}

Due to a large number of measurements, the authors decided that average effectiveness is not sufficient to assess the real performance of the heat exchanger. A more detailed analysis of the frequency distribution of a set of results, which allows the visualization and inspection of the data, has been proposed. For this purpose, a histogram of total effectiveness results was prepared. The relative frequency as the percentage ratio of the results in a given range to the number of all obtained values was used. The graph is presented in Figure 7.

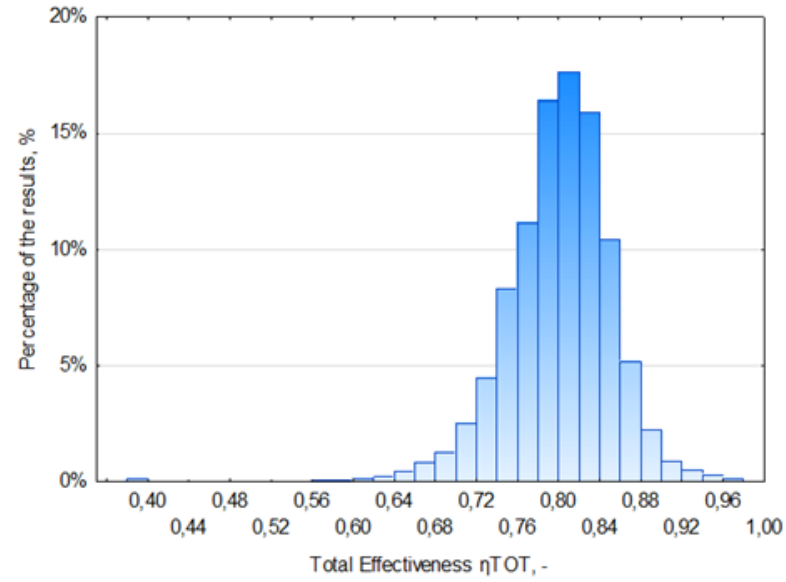

Fig. 7. Histogram of the total effectiveness result

In the next stage, the authors decided to assess the relationship between the total effectiveness of the system and two key parameters: temperature and humidity of the outside air. Figure 8 shows the relationship between the total energy transfer effectiveness and the outside air temperature.

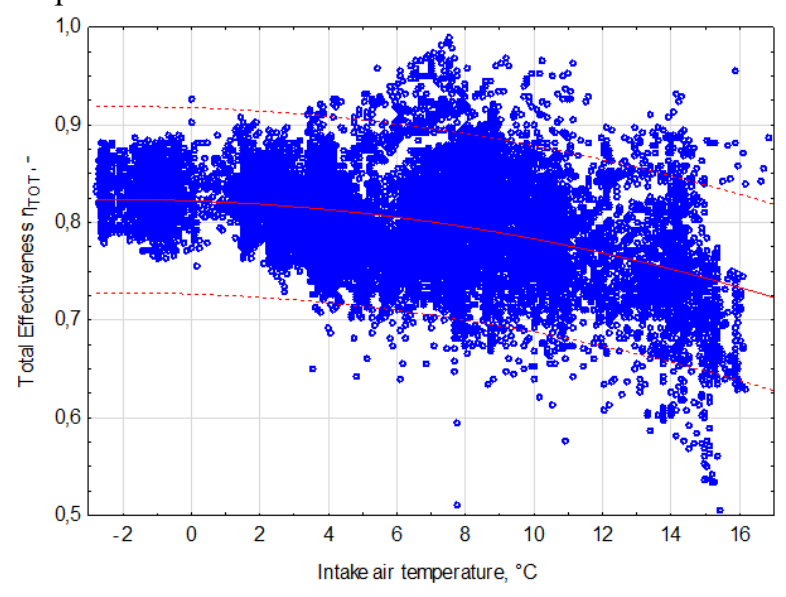

Fig. 8. The total effectiveness of the heat recovery system depending on the intake temperature 
The chart shows the temperature range for which the most results were obtained. The extreme values have been rejected as uncertain records. There is a noticeable decreasing trend. At temperatures in the range from -3 to $2^{\circ} \mathrm{C}$, the effectiveness of the system is very high and varies from 0.75 to 0.9 . At higher temperatures, the effectiveness varies over a wider range, and decreasing correlation is more visible.

Figure 9 shows the correlation between total energy transfer effectiveness and relative air humidity in a similar way.

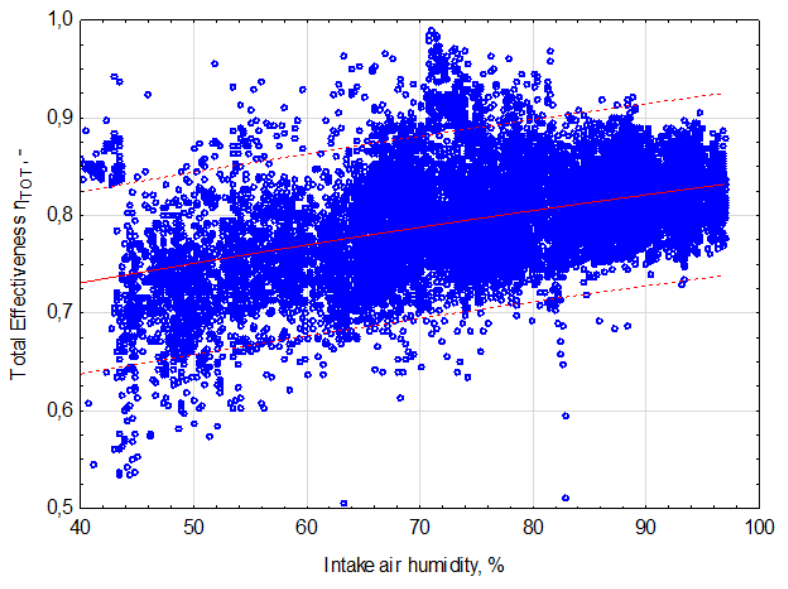

Fig. 9. The total effectiveness of the heat recovery system depending on the intake relative humidity

In this case, the dependence is increasing, and the smallest deviations from the average effectiveness value for a given humidity were achieved for the relative humidity $85-95 \%$.

\section{Conclusion}

The subject of the work is a ventilation system with heat recovery. The analysed system provides air exchange in guests' rooms. The hotel is located in southern Poland. The calculation was performed based on collected data from the cold period. In the paper, the temperature and humidity variability in the daily cycle was presented, and the heat recovery effectiveness was evaluated. To determine the effectiveness, three commonly used indicators were applied: sensible ratio, latent ratio, and total transfer energy effectiveness. Data after appropriate conversions are presented in the charts. Figures 8 and 9 show the relationship between the total recovery effectiveness and temperature and humidity, respectively. There are an apparent trend and dependence in both relationships. The analysis showed that the application of a highly efficient heat exchanger with moisture recovery obtains a very satisfactory effect. The average sensible and latent energy recovery effectiveness coefficients calculated based on the collected data were $88.14 \%$ and $55.11 \%$, respectively. The average total effectiveness of the entire system was estimated at the level of $80.02 \%$. Due to the frequent date recording (temporal resolution equal 60 seconds) and wide measurement period, the variability of the obtained performance indicators is significant. Therefore, the calculation of the average results may be insufficient to present the real efficiency of the solution. Figure 7 shows the variability of total effectiveness according to the percentage share of each effectiveness interval. Almost $95 \%$ of the measurements carried out allowed to obtain the total effectiveness in the range from 70 to $90 \%$. According to the examples provided in the introduction chapter, it is noticeable that the proposed system achieves very good efficiency characteristics. It is worth noting that the analysis was performed for real conditions, not on a laboratory stand. Therefore, both internal and external conditions were changing very dynamic. The variability of internal air parameters is particularly significant in hotels, where the air parameters are affected by the presence and activity of hotel guests.

In conclusion, the application of this solution for the analysed hotel provided very satisfactory results. This type of heat exchanger can help adapt the building to the requirements of nearly zero-energy buildings and bring long-term economic benefits.

\section{Nomenclature}

$\mathrm{RH}$ - relative humidity, \%

$V$ - volume flow rate, $\mathrm{m}^{3} / \mathrm{h}$

$\dot{M}$ - mass flow rate, $\mathrm{kg} / \mathrm{s}$

$\mathrm{x}$ - moisture content, $\mathrm{kg}$ moisture $/ \mathrm{kg}$ dry air

$p_{w s}$ - saturation vapour pressure, $\mathrm{Pa}$

$\eta_{\mathrm{T}}-$ sensible energy effectiveness, -

$\eta_{\mathrm{H}}$ - latent energy effectiveness, -

$\eta_{\text {тот }}$ - total energy transfer effectiveness,-

\section{References}

1. Global ABC, IEA and UNEP 2019 Global Status Report for Buildings and Construction: Towards a zero-emission, efficient and resilient buildings and construction sector (2019)

2. IEA, Energy Effectiveness 2020, IEA, Paris https://www.iea.org/reports/energy-effectiveness2020.

3. Directive 2010/31/EU of the European Parliament and of the Council of 19 May (2010)

4. Directive 2012/27/EU of the European Parliament and of the Council of 25 Oct. (2012)

5. A. Mardiana-Idayu, S.B. Riffat, Renew. Sustain. Energy Rev. 16, 1241-1255 (2012).

6. D. Hunt, N. Mac Suibhne, L. Dimache, D. McHugh, J. Lohan, E3S Web Conf. 111, 01010 (2019)

7. M. Borowski, M. Jaszczur, D. Satoła, S. Kleszcz, M. Karch, MATEC Web Conf. 240, 02003 (2018)

8. P. Michalak, S. Grygierczyk, J Mech Energy Eng. 3(3), 267-272 (2019)

9. J. Zemitis, A. Borodinecs A., IOP Conf. Ser.: Mater. Sci. Eng. 660, 012019 (2019)

10. M. Jaszczur, S. Kleszcz, M. Borowski, E3S Web of Conferences, 108, 01022 (2019)

11. EN ISO 15927-4:2005 Hygrothermal performance of buildings - Calculation and presentation of 
climatic data - Part 4: Hourly data for assessing the annual energy use for heating and cooling

12. ASHRAE Handbook - Fundamentals, SI edition, ASHRAE, Atlanta (2017)

13. ASHRAE Handbook - HVAC Systems and

Equipment, SI edition, ASHRAE, Atlanta (2016) 